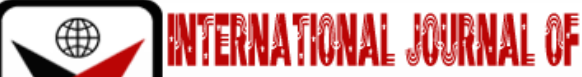

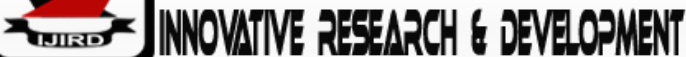

ISSN 2278-0211 (Online)

\section{Graphic Design Effects on Consumer Online Purchase and Referral Intentions in Ghana's Hospitality Industry: The Connections and the Mediating Role of Consumer Website Visit Satisfaction}

\begin{tabular}{c}
\hline Solomon Bawuah \\
Student, Department of Fine Arts, Jiangsu University, China \\
Dr. Zhe Zhu \\
Professor, Department of Fine Arts, Jiangsu University, China \\
\hline
\end{tabular}

\begin{abstract}
:
The Mehrabian and Russell's Stimulus-Organism-Response model was used to link and test the relationship between the predictor external variables (i.e., website artistic design (WAD), quality of information (QI)) as stimuli and the online purchase intention (PI) of consumers and referral intention (RI) as responses. The hedonic factor in this model was the satisfaction derived by consumers as a result of visiting the website. A test of the relationship between the WAD (stimulus), QI influenced by the design and text (organism) and the PI and RI (responses) was carried out using multiple regression analysis. Also, the Hayes' Process macro tool-pack of IBM-SPSS (Version 25) was used to assess the potential mediation function of consumer website visit satisfaction (CWVS) (measured by likeability and comfort) on the relationship between WAD or QI and PI and RI. Findings showed a strong positive relationship between WAD and PI $\left(r^{2}=0.550\right)$ and RI $\left(r^{2}=0.491\right)$ and between QI and PI $\left(r^{2}=0.421\right)$, but not $R I\left(r^{2}=0.194\right)$. CWVS successfully mediated the relationships between WAD and PI, but not between WAD and RI. It also successfully mediated the relationships between QI and PI and RI. Results have shown that the satisfaction of consumers online was significantly dependent on WAD and QI and was needed for sustained PI and RI.
\end{abstract}

Keywords: Website graphic design, consumer satisfaction, social media marketing, online marketing, online purchase, purchase intention, referral intention

\section{Introduction}

Graphic design is a user-centered subject related to the aesthetic characteristics of any form of art, and is used to beautify and make websites and other platforms appealing to consumers whiles enhancing information quality (Frascara, Meurer, van Toorn, \& Winkler, 1997). Graphic design is closely linked with communication as designs always carry peculiar messages (Frascara et al., 1997). In the tourism industry such as hotels, the aesthetic characteristics of properties (i.e., buildings, landscapes, facilities, etc.) are mostly used to market them (Alfakhri, Harness, Nicholson, \& Harness, 2018; Witz, Warhurst, \&Nickson, 2003; Xu \&Schrier, 2019). According to studies, the aesthetic features of hotels and tourist sites are key determinants of consumer choice for recreational venue (Breiby\&Slåtten, 2018; Kirillova, Fu, Lehto, \& Cai, 2014; Kirillova\&Lehto, 2015; MacKay \&Fesenmaier, 1997). The recent trend of digital marketing has compelled many hospitality organizations to adopt the use of the internet such as websites and other online social media platforms for marketing and selling their services (Chan \&Guillet, 2011; Tatar \&Eren-Erdoğmuş, 2016). It is difficult to discuss the use of digital marketing in the hospitality industry without mentioning the role of graphic design (Kasavana, 2000; Kasavana, Knutson, \&Polonowski, 1998). Not only is graphic design used to make websites and online platforms attractive, but also used to convey varying information useful to consumers in decision and choice making processes (Cao, Zhang, \&Seydel, 2005; Eppler, 2006; Rieh, 2002). Most of these mobile applications and the use of the internet and websites cannot be done without graphic design to convey the right information while ensuring aesthetics and consumer entertainment through nerve-calming images and designs, hence the need to study the effects of graphic design on business sustainability through online PI and RI.

Since the 2000s in Ghana and in many other developing countries, the use of digital platforms and internet for business is becoming the norm and consumers are getting used to the change (Akomea-Bonsu\&Sampong, 2012). Although there are still challenges, the positive effects cannot be overlooked (Ewusi-Mensah, 2012). Many mobile application platforms are being customized for organizations in the hospitality industry for the purposes of marketing and booking or reservation of spaces and services of varying characteristics (Dayour, Adongo, \&Agyeiwaah, 2020; Mahmoud, Kastner, \&Lartey, 2017). Consumers no longer travel to venues to be able to make reservations and payments due to the 
availability and the operability of these online platforms such as Facebook, Instagram, WhatsApp and organizational websites (Perrin, 2015). These features, now available at the fingertips of consumers, make it convenient in difficult times such as in dealing with the covid-19 and other pandemics (Gentilini, Almenfi, Orton, \& Dale, 2020) for consumers to buy, reserve or even cancel transactions with minimum risk and with financial security (Shaw, Kim, \& Hua, 2020). Other scholars are even advocating for electronic tourism (E-tourism) (Gretzel et al., 2020).

Apart from the aesthetic and other marketing functionalities that graphic design can enhance, it also has a significant influence on information seeking behaviour and information use among consumers. Interactive information seeking behaviour and retrieval are influenced by deign of website (Ruthven \& Kelly, 2011). Also, among children and the youth, graphics are used to focus attention and induce interest in online and hard information (Dresang, 2005). The graphic design of user-interfaces for online databases has been shown to significant influence information seeking behaviour of users (AAZAMI \&Fatahi, 2010). The design of websites, for example, affects the comfort level (Currie, McGrath, \& Day, 2010), interest (Collins, 2018), ability to capture relevant information (Marchionini\&Komlodi, 1998), filtering, and even the length of time spent seeking information. It can also influence consumer satisfaction with information seeking and encourages word-of-mouth (WOM) referrals (Duarte, e Silva, \& Ferreira, 2018). Attractive designs with concise and relevant information attract more traffic than those which are less attractive and with either too much, too little or irrelevant information. The blend of colors in designs is relevant for consumer comfort and emotion, considering the psychological connection between colors and mood (Cheng, Wu, \& Yen, 2009). Another study has also shown that colors affect consumer mood, memorization of information and online purchase intention (Pelet\&Papadopoulou, 2012). The importance of graphic design in social media and digital management of businesses cannot be overemphasized, especially in the hospitality industry in Ghana. However, little information is available about its effects in this sector in the country.

\section{Conceptual Framework and Study Hypotheses}

The concept and the theory of this study is based primarily on the Stimulus-Organism-Response model of Mehrabian and Russell. It is understood that stimuli from the environment and the inherent nature of an individual, when mixed with emotional and /or cognitive features which define that individual as an organism, result in a response. In this context, WAD and QI (stimuli) can influence the level of satisfaction of a consumer (organism) and may lead to the intention of purchasing an item online (PI) and /or referring others to do same (RI) (Figure 1).

The hypotheses of this study are based on literature and the expectations of the authors and are considered the potential outcomes of the study unless disproved. WAD is a variable that directly relates with how aesthetic a website looks based on its graphic design, and it is expected that it will positively correlate and significantly influence the level of satisfaction a consumer derives from online visits (CWVS). According to a study, an online website visitor's first impression based on page design, layout and color influence satisfaction significantly (Liu, He, Gao, \&Xie, 2008).

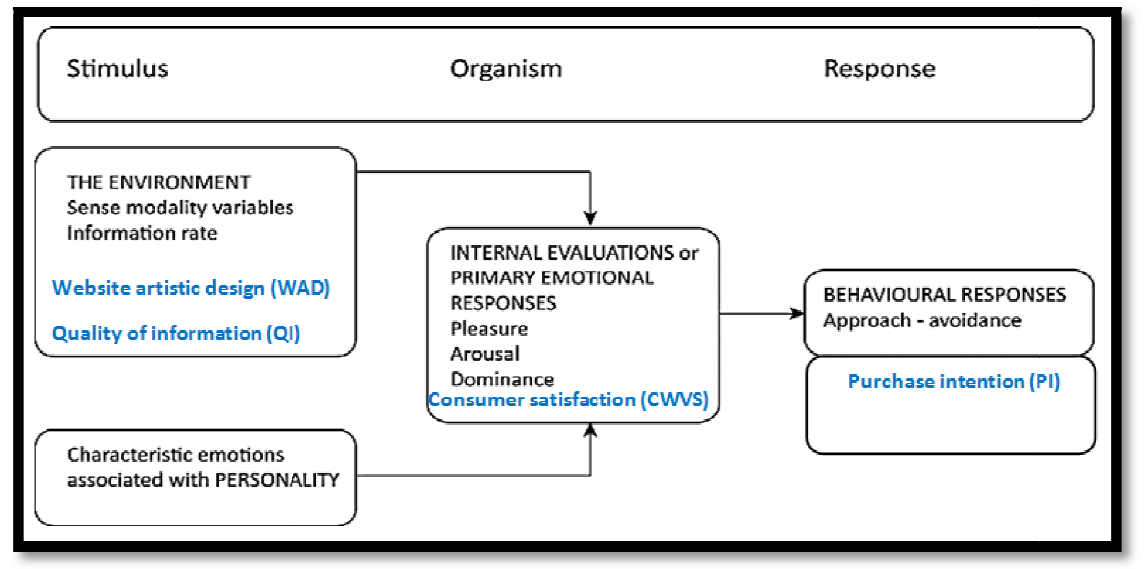

Figure 1: Conceptual Framework Based on the Stimulus-Organism- Model (Mehrabian\&Russell, 1974)

In the e-banking sector, graphic design was shown to influence customer satisfaction (Ahmad \& Al-Zu'bi, 2011). Base on these confirmatory reports from other scholars, it is the expectation of the authors that WAD will significantly and positively influence CWVS $\left(\mathrm{H}_{1}\right)$.

- $\quad H_{1}:$ WAD will significantly and positively influence CWVS.

On another hand, PI and RI can be said to be influenced significantly by customer satisfaction. It is logical and natural that customers only purchase online after their expectations are met or when they are satisfied. This has been proven by many studies done by other scholars (Ali, 2016; Hasanov\& Khalid, 2015; Hsu, Chang, \& Chen, 2012; Jiradilok, Malisuwan, Madan, \&Sivaraks, 2014). It is also reasonable that they only recommend a product or service to others based on the satisfaction they derive from doing same online (Wangenheim\&Bayón, 2007) $\left(\mathrm{H}_{2}\right)$. Although these connections are confirmed, they may vary from setting to setting based on cultural differences and the ability of customers to appreciate the effect of graphic design in online marketing and purchasing (Lee, Joshi, \& Bae, 2009).

- $\mathrm{H}_{2}$ : CWVS will successfully mediate the relationship between WAD and PI and RI

- $\mathrm{H}_{3}$ : QI will significantly and positively influence CWVS

- $\mathrm{H}_{4}$ : CWVS will successfully mediate the relationship between QI and PI and RI 


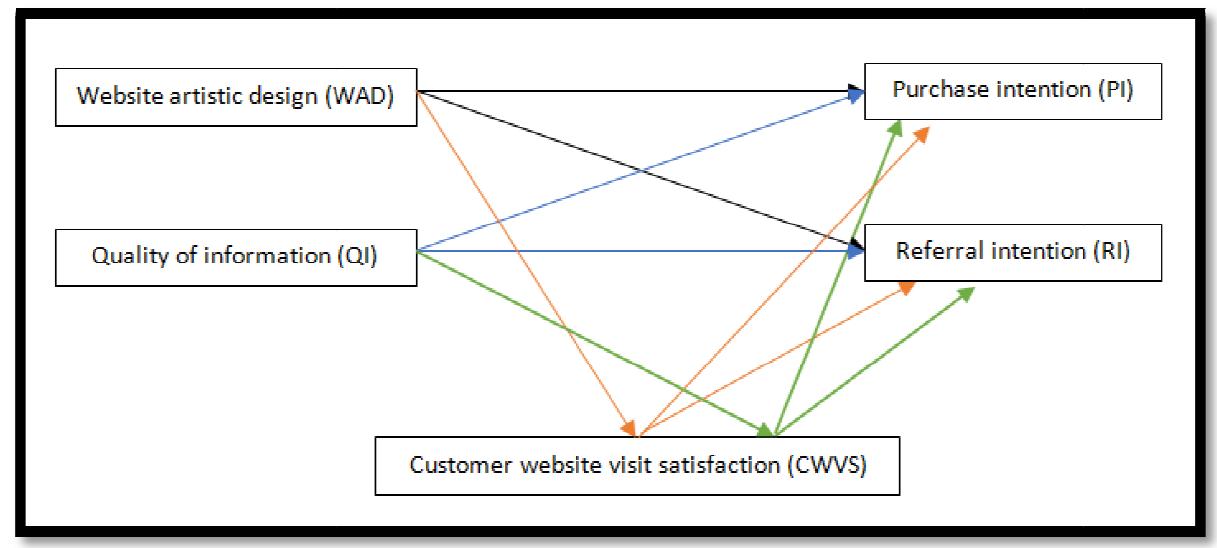

Figure 2: Analytical Framework

Black and blue lines depict direct relationships between predictor and response variables and orange and green lines depict mediation of CWVS on the direct relationships.

Separately, Figure 2 can be redrawn for each main relationship as shown in Figure 3 and Figure 3B.

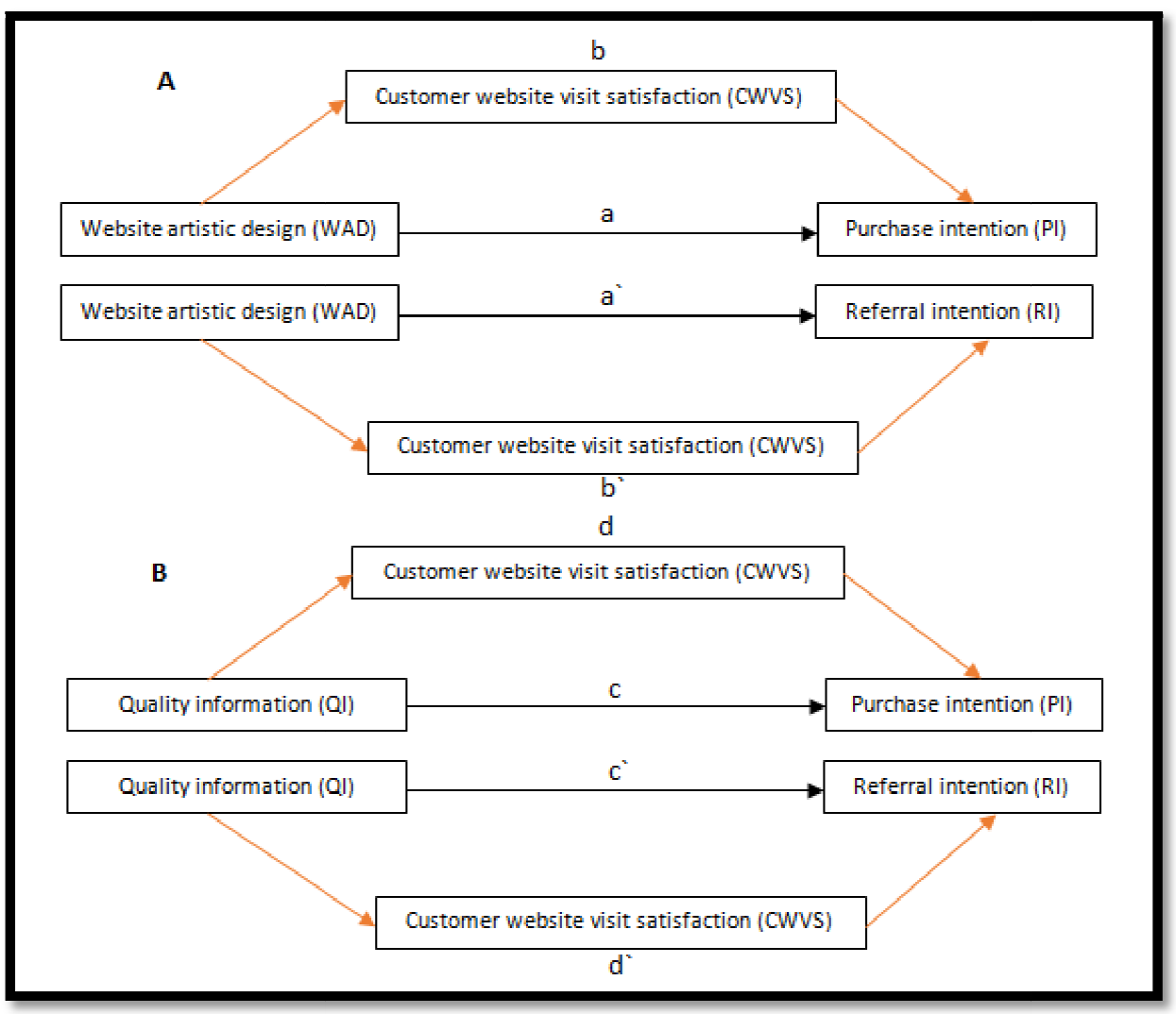

Figure 3: Direct Relationship between WAD and PI Is Depicted Using a and the CWVS Mediation Is Shown Using B. Direct Relationship Between WAD and RI And CWVS Mediation Are Respectively Shown Using A'and B`. Direct Relationship between QI and PI Is Depicted Using C and the CWVS Mediation Is Shown Using D. Direct Relationship between QI and RI and CWVS Mediation Are Respectively Shown Using C' and D

\section{Methodology}

\subsection{Data Collection}

A cross-sectional online survey was used to administer questionnaires to individuals who use digital platforms and the internet to seek information, make choices about products and services in the hospitality industry, make reservations and payments. These individuals were contacted through emails and social media platforms. These were the most appropriate means to use during the covid-19 pandemic to limit risk to both researchers and respondents. A total of 1500 electronic questionnaires were sent out through the earlier mentioned platforms and data were quantitatively assessed for 1283 responses. The Mehrabian and Russell's Stimulus-Organism-Response model was used to link and test the relationship between the predictor external variables (i.e., website artistic design (WAD), quality of information (QI) as stimuli and the online purchase intention (OPI) of consumers and referral intention (RI) as responses. 


\subsection{Data Analyses}

A test of the relationship between the WAD (stimulus), the cognitive ability of synthesizing information (QI), influenced by the design and text (organism) and the PI and R intention (I) (responses) was carried out using multiple regression analysis. Also, the Hayes' Process macro tool-pack of IBM-SPSS (Version 25) was used to assess the potential mediation function of consumer website visit satisfaction (CWVS) (measured by likeability and comfort) on the relationship between WAD and PI and RI. Multiple collinearity tests measured by variance inflation factor (VIF) was used to test the statistical validity of the model for mediation analysis. Statistical significance was measured at a CI of $95 \%$.

\section{Results and Discussion}

\subsection{Descriptive Statistics and Model Fitness}

Normality of data was checked for statistical fitness for regression assessment confirmed with correlation matrix for collinearity checks between variables (Table 1) as well as VIF. Residual plot of data was also used to confirm adequacy of the statistical method used (Figure 4). Mean values for variables were $16.83 \pm 3.78,17.05 \pm 1.41,19.44 \pm 2.02$ and 19.70 \pm 1.93 for WAD, QI, PI and RI respectively.

\subsubsection{Correlational Analysis}

According to the rules for data fitness for multiple regression analysis, significant correlations between response and predictor variables are good whereas low or poor correlations between predictor variables alone show no multicollinearity. Table 1 shows a strong positive relationship between WAD and the response variables, PI $\left(\mathrm{r}^{2}=0.550\right.$, $\mathrm{p}<0.01)$ and RI $\left(\mathrm{r}^{2}=0.491, \mathrm{p}<0.05\right)$. Further a significant positive relationship was observed between QI and PI ( $\mathrm{r} 2=$ 0.421, $\mathrm{p}<0.05$ ). QI and RI did not correlate strongly ( $\mathrm{r} 2=0.194, \mathrm{p}>0.05$ ) (Table 1).

\begin{tabular}{|c|c|c|c|c|c|c|}
\hline & & WAD & QI & PI & $\mathbf{R I}$ & CWVS \\
\hline \multirow[t]{3}{*}{ WAD } & Pearson Correlation & 1 & & & & \\
\hline & Sig. (2-tailed) & & & & & \\
\hline & $\mathrm{N}$ & 1283 & & & & \\
\hline \multirow[t]{3}{*}{ QI } & Pearson Correlation & 0.246 & 1 & & & \\
\hline & Sig. (2-tailed) & 0.720 & & & & \\
\hline & $\mathrm{N}$ & 1283 & 1283 & & & \\
\hline \multirow[t]{3}{*}{ PI } & Pearson Correlation & $0.550^{* *}$ & $0.421^{*}$ & 1 & & \\
\hline & Sig. (2-tailed) & 0.013 & 0.029 & & & \\
\hline & $\mathrm{N}$ & 1283 & 1283 & 1283 & & \\
\hline \multirow[t]{3}{*}{ RI } & Pearson Correlation & $0.491^{*}$ & 0.194 & 0.200 & 1 & \\
\hline & Sig. (2-tailed) & 0.018 & 0.811 & 0.771 & & \\
\hline & $\mathrm{N}$ & 1283 & 1283 & 1283 & 1283 & \\
\hline \multirow[t]{3}{*}{ CWVS } & Pearson Correlation & $0.602^{* *}$ & $0.498^{*}$ & $0.394^{*}$ & 0.211 & 1 \\
\hline & Sig. (2-tailed) & 0.004 & 0.012 & 0.447 & 0.703 & \\
\hline & $\mathrm{N}$ & 1283 & 1283 & 1283 & 1283 & 1283 \\
\hline \multicolumn{5}{|c|}{$\begin{array}{l}\text { ** and }{ }^{*} \text { show significance at the } 0.01 \text { and } 0.05 \text { levels, respectively } \\
\text { (2-tailed). }\end{array}$} & $\mathrm{N}$ & \\
\hline
\end{tabular}

Table 1: Correlation Matrix Depicting the Relationship between Study Variables

$\mathrm{H}_{1}$, which stated that WAD will positively and significantly influence CWVS, can be assessed using Table 1 . A strong and positive correlation (0.602) between the two terms showed that H1 was accepted as was confirmed in earlier studies done by others (Ali, 2016; Hasanov\& Khalid, 2015; Hsu et al., 2012; Jiradilok et al., 2014). The link between WAD, consumer comfort, mood, emotions, and the effects of WAD on the aesthetic properties of a website confirms this observation which was confirmed in several other studies.

$\mathrm{H}_{3}$ stated that QI will significantly and positively influence CWVS, and according to a correlation coefficient of 0.498 (Table 1) confirmed it as was observed in other studies. A correlation of 0.380 was observed between the quality of website information and customer satisfaction in a similar study (Liang \& Chen, 2009). Therefore, H3 was accepted as well.

\subsubsection{Residual Plot of Normality}

This plot is an expression of the closeness of observed values to their true values and how much they deviate from their means. It also helps identify extraneous variables that make the data unfit for statistical exploration. Figure 4 shows that the data for this study are fit for purpose, backed by a proof of normality of distribution. 


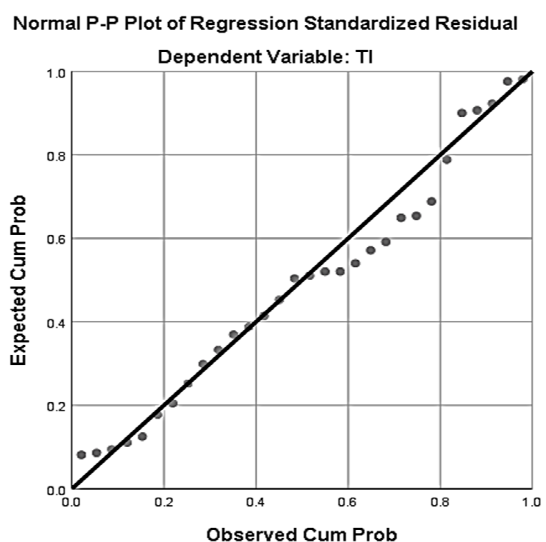

Figure 4:Standardized Residual Plot

\subsection{Regression Analyses}

The regression model was significant and suitable for the objective of establishing the relationship between either WAD or QI and PI and RI, considering the mediating roles of CWVS (Figure 3). Summary data for the WAD-PI model and analysis of variance (ANOVA) confirmed statistical significance $(\mathrm{p}<0.05)$. Test statistics show $\mathrm{R}^{2}$ and adjusted $\mathrm{R}^{2}$ values of 0.797 and 0.635 respectively, which showed that predictor variables were capable to predict up to $79.7 \%$ of the variability observed in the response variable, which is good for the analysis. The $\mathrm{R}^{2}$ and adjusted $\mathrm{R}^{2}$ values of the WAD-RI model were 0.664 and 0.593 respectively. For the QI-PI and QI-RI models, the respective $\mathrm{R}^{2}$ and adjusted $\mathrm{R}^{2}$ values were 0.601 and 0.565 and 0.710 and 0.648 . All models of the study were statistically significant $(\mathrm{p}<0.05)$. The regression analyses followed Equation 1.

$\gamma=\beta_{0}+\beta_{1} X_{1}+\beta_{2} X_{2}+\varepsilon$

where $\beta_{0}, \beta_{1}$ and $\beta_{2}$ are the regression coefficients for the constant, WAD or QI and CWVS respectively, and $\varepsilon$ the error term.

For the WAD-PI model, Equation 1 becomes $\mathrm{PI}=\beta_{0}+\beta_{1} W A D+\beta_{2} C W V S$, considering no errors. From the regression coefficients in Table 2 , PI $=6.227 \pm 1.201+0.514 \pm 0.091$ WAD $+0.381 \pm 0.136$ CWVS.This meant that for every unit increase in WAD, there is a $51.4 \%$ chance of increasing PI, holding all other variables constant. Also, for every increase in CWVS, there is a $38.1 \%$ chance of increasing PI.

\begin{tabular}{|c|c|c|c|c|c|c|}
\hline \multirow{2}{*}{ Model } & \multicolumn{2}{|c|}{$\begin{array}{c}\text { Unstandardized } \\
\text { Coefficients }\end{array}$} & $\begin{array}{c}\text { Standardized } \\
\text { Coefficients }\end{array}$ & \multirow{2}{*}{ Sig. } \\
\cline { 3 - 5 } \multicolumn{2}{|c|}{} & B & Std. Error & Beta & & \\
\hline \multirow{3}{*}{1} & (Constant) & 6.227 & 1.201 & & 2.361 & 0.012 \\
\cline { 2 - 6 } & WAD & 0.514 & 0.091 & 0.495 & 3.442 & 0.002 \\
\cline { 2 - 6 } & CWVS & 0.381 & 0.136 & 0.275 & 4.003 & 0.001 \\
\hline \multicolumn{7}{|c|}{ Dependent Variable: PI } \\
\hline
\end{tabular}

Table 2: Model Coefficients for WAD-PI

For the WAD-RI model, $\mathrm{RI}=\beta_{0}+\beta_{1} W A D+\beta_{2} C W V S$ From Table 3, RI $=5.395 \pm 2.099+0.402 \pm 0.130 \mathrm{WAD}+$ $0.397 \pm 0.055 \mathrm{CWVS}$. This meant that for every unit increase in WAD, a $40.2 \%$ chance of increasing RI exists, ceteris paribus. Also, for every increase in CWVS, a $39.7 \%$ chance of increasing RI exists.

\begin{tabular}{|c|c|c|c|c|c|c|}
\hline \multirow{2}{*}{ Model } & \multicolumn{2}{|c|}{$\begin{array}{c}\text { Unstandardized } \\
\text { Coefficients }\end{array}$} & $\begin{array}{c}\text { Standardized } \\
\text { Coefficients }\end{array}$ & \multirow{2}{*}{ Sig. } \\
\cline { 3 - 7 } \multicolumn{2}{|c|}{} & B & Std. Error & Beta & & \\
\hline \multirow{3}{*}{1} & (Constant) & 5.395 & 2.099 & & 2.273 & 0.010 \\
\cline { 2 - 7 } & WAD & 0.402 & 0.130 & 0.388 & 2.752 & 0.000 \\
\cline { 2 - 6 } & CWVS & 0.397 & 0.555 & 0.174 & 3.301 & 0.001 \\
\hline \multicolumn{7}{|c|}{ Dependent Variable: RI } \\
\hline
\end{tabular}

Table 3: Model Coefficients for WAD-RI

For the QI-PI model, $\mathrm{PI}=\beta_{0}+\beta_{1} Q I+\beta_{2} C W V S$. From Table 4 , PI $=5.111 \pm 2.003+0.488 \pm 0.227 \mathrm{QI}+0.300$ $\pm 0.102 \mathrm{CWVS}$.Holding all variables constant, a unit increase in QI has a $48.8 \%$ chance of increasing PI and every unit increase in CWVS gives a $30.0 \%$ chance of increasing PI. 


\begin{tabular}{|c|c|c|c|c|c|c|}
\hline \multicolumn{2}{|c|}{ Model } & \multicolumn{2}{c|}{$\begin{array}{c}\text { Unstandardized } \\
\text { Coefficients }\end{array}$} & $\begin{array}{c}\text { Standardized } \\
\text { Coefficients }\end{array}$ & \multirow{2}{*}{ Sig. } \\
\cline { 3 - 7 } \multicolumn{2}{|c|}{} & B & Std. Error & Beta & & \\
\hline \multirow{2}{*}{1} & (Constant) & 5.111 & 2.003 & & 2.551 & 0.000 \\
\cline { 2 - 7 } & QI & 0.488 & 0.227 & 0.405 & 3.029 & 0.003 \\
\cline { 2 - 6 } & CWVS & 0.300 & 0.102 & 0.280 & 4.014 & 0.001 \\
\hline \multicolumn{7}{|c|}{ Dependent Variable: PI } \\
\hline
\end{tabular}

Table 4: Model Coefficients for QI-PI

For the QI-RI model, $\mathrm{RI}=\beta_{\mathrm{o}}+\beta_{1} Q I+\beta_{2} C W V S$. From Table 5, RI $=4.990 \pm 1.344+0.337 \pm 0.103 \mathrm{QI}+$ $0.151 \pm 0.096 \mathrm{CWVS}$. Holding all variables constant, a unit increase in QI has a $33.7 \%$ chance of increasing RI and every unit increase in CWVS gives a $15.1 \%$ chance of increasing RI. The effect of CWVS on RI was not significant ( $p>0.05$ ). This was reflected in its poor correlation with RI in Table 1 although a positive relationship was observed, contrary to observations made in some earlier studies (Wangenheim\&Bayón, 2007). However, CWVS has positively and significantly influenced both PI and RI when considering the effect of WAD as shown in Tables 2, 3 and for QI in Table 4, all confirming $\mathrm{H}_{1}$.

\begin{tabular}{|c|c|c|c|c|c|c|}
\hline \multirow{2}{*}{ Model } & \multicolumn{2}{|c|}{$\begin{array}{c}\text { Unstandardized } \\
\text { Coefficients }\end{array}$} & $\begin{array}{c}\text { Standardized } \\
\text { Coefficients }\end{array}$ & \multirow{2}{*}{ Sig. } \\
\cline { 3 - 7 } \multicolumn{2}{|c|}{} & B & Std. Error & Beta & & \\
\hline \multirow{3}{*}{1} & (Constant) & 4.990 & 1.344 & & 3.128 & 0.032 \\
\cline { 2 - 6 } & QI & 0.337 & 0.103 & 0.320 & 3.000 & 0.013 \\
\cline { 2 - 6 } & CWVS & 0.151 & 0.096 & 0.122 & 2.564 & 0.061 \\
\hline \multicolumn{7}{|c|}{ Dependent Variable: RI } \\
\hline
\end{tabular}

Table 5: Model Coefficients for QI-RI

\subsection{Mediation Effects of CWVS}

\subsubsection{Mediation Role of CWVS on the WAD-PI and WAD-RI Relationships}

Using the PROCESS macro application of Hayes (2018), the mediation effect of CWVS on the relationship between WAD and PI was tested according to the conceptual framework and study hypothesis $\left(\mathrm{H}_{2}\right.$ : CWVS will successfully mediate the relationship between WAD and PI and RI).

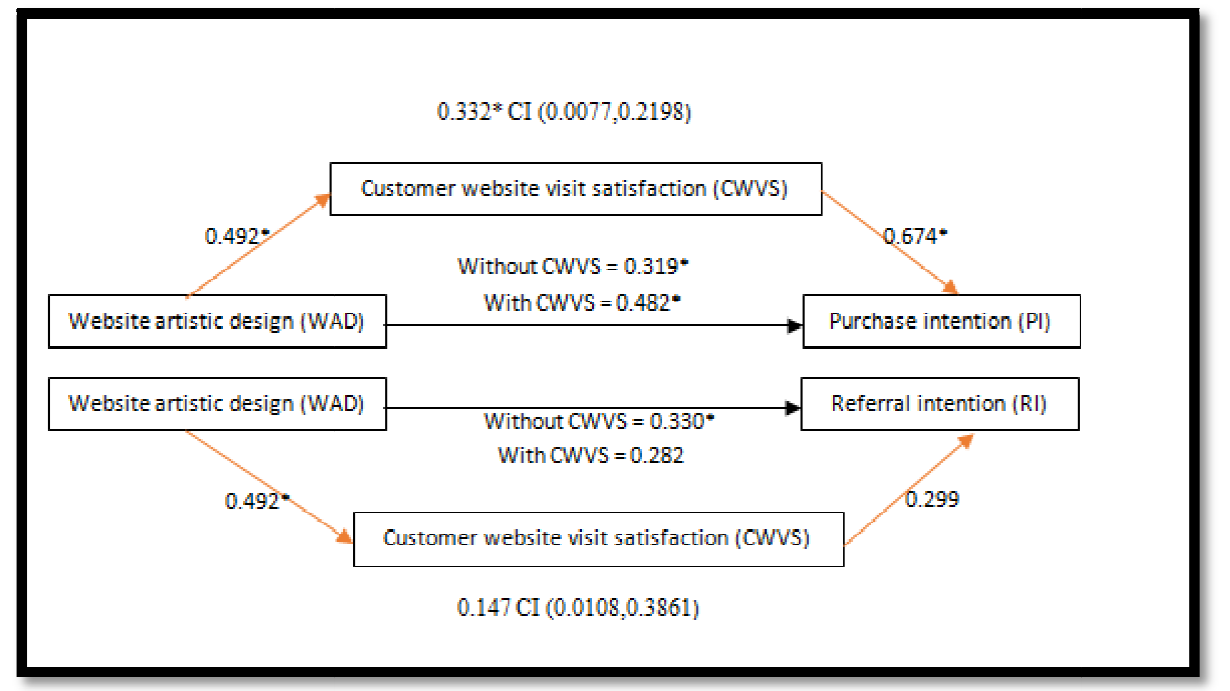

Figure 5: Mediation Test of CWVS on the WAD-PI/RI Models.

* Shows Significance at a 95\% CI.

The model for assessing mediation was significant $(\mathrm{p}<0.05)$. CWVS successfully mediated the WAD-PI relationship with an indirect effect coefficient of 0.332 with lower and upper CI being 0.0077 and 0.2198 respectively, higher than a direct effect correlation of 0.319 (Figure 5). However, CWVS did not mediate the effect of WAD on RI, having a lover indirect effect $\left(\mathrm{r}^{2}=0.147\right)$ than a direct WAD-RI coefficient of 0.330 (Figure 5). Therefore, $\mathrm{H}_{2}$ can only be partially accepted because the WAD-RI relationship was not significantly mediated by CWVS. 


\subsubsection{Mediation Role of CWVS on the WAD-PI and WAD-RI Relationships}

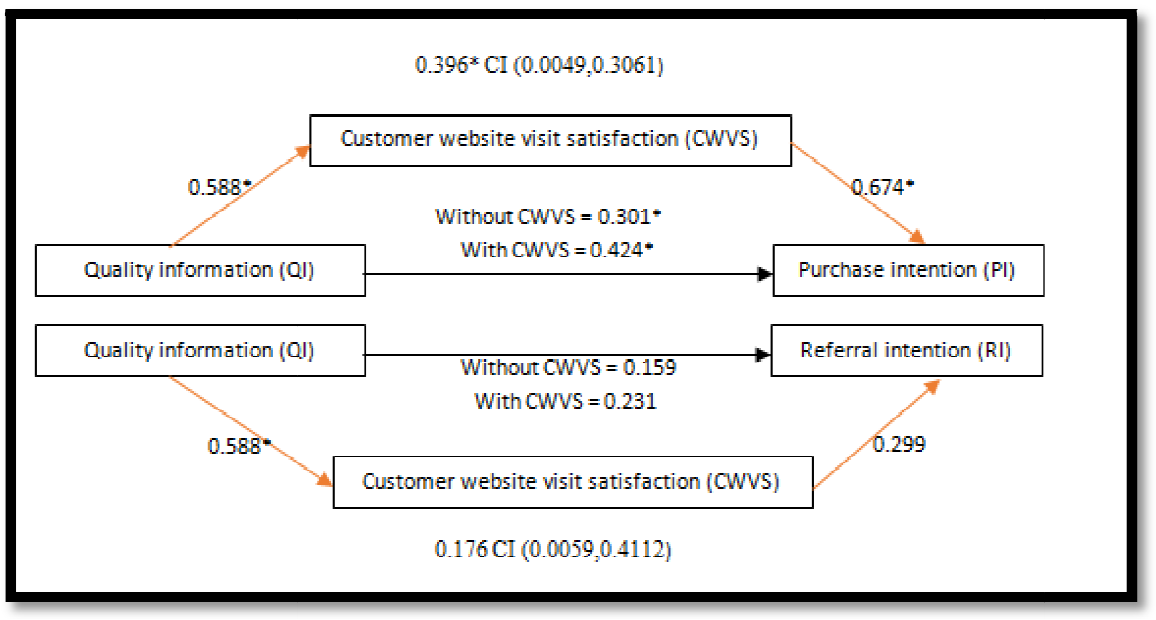

Figure 6: Mediation Test of CWVS on the QI-PI/RI Models

* Shows Significance at a $95 \%$ CI

The mediation role of CWVS on the relationship between QI and PI/RI was significant for both models. Although QI did not significantly influence RI, it indirectly did through the mediation effect of with a coefficient of 0.176 higher than a direct effect coefficient of 0.159 (Figure 6). From this test, it was shown that CWVS is important to enhance PI and RI even when there is good QI on websites of marketing organizations. This analysis confirms the acceptance of $\mathrm{H}_{4}$.

Online purchase within the tourism sector was found to be mediated by customer satisfaction in determining the e-loyalty of customers (Pereira, de FátimaSalgueiro, \& Rita, 2016). Another study examined the determinants of repeat purchase intention, considering the mediating effect of customer satisfaction. Results revealed that customer satisfaction significantly mediated the relationship between product attribute and online repeat purchase intention among Malaysians (Goh, Jiang, Hak, \& Tee, 2016). Moreover, the satisfaction of customers online has been shown in some other studies to mediate the relationship between website service quality and repurchase intention, in agreement with the observations made in this study (Shukla, Sharma, \& Swami, 2010; Tandon, Kiran, \&Sah, 2017).

\section{Conclusion}

The effect of WAD and QI on CWVS, PI and RI were measured, and the mediating effects of CWVS on the relationships between the predictor and response variables were also assessed. The entire concept of the study was based on the Mehrabian and Russell's Stimulus-Organism-Response model. Findings showed a strong positive relationship between WAD and PI and RI and between QI and PI, but not RI. CWVS successfully mediated the relationships between WAD and PI, but not between WAD and RI. It also successfully mediated the relationships between QI and PI and RI. Results have shown that the satisfaction of consumers online was significantly dependent on WAD and QI and was needed for sustained PI and RI.

The importance of customer satisfaction for online marketing and tourism organizations cannot be overemphasized, given the backings from other literature on the subject. Although, WAD and QI were able to influence PI and RI, their influences were amplified when online customers are satisfied with what they see and what information they read on the websites of tourism organizations in this context. Future studies can consider the effect of gender, geographical location, and socio-economic factors on online purchase and referral intentions of customers in the hospitality and tourism industries.

\section{References}

i. AAZAMI, M., \&Fatahi, S. (2010). Database graphic user interface correspondence with Ellis information seeking behavior model.

ii. Ahmad, A., \& Al-Zu'bi, H. A. (2011). E-banking functionality and outcomes of customer satisfaction: an empirical investigation. International journal of marketing studies, 3(1), 50-65.

iii. Akomea-Bonsu, C., \&Sampong, F. (2012). The impact of information and communication technologies (ICT) on small and medium scale enterprises (SMEs) in the Kumasi Metropolis, Ghana, West Africa. European Journal of Business and Management, 4(20), 152-158.

iv. Alfakhri, D., Harness, D., Nicholson, J., \& Harness, T. (2018). The role of aesthetics and design in hotelscape: A phenomenological investigation of cosmopolitan consumers. Journal of business research, 85, 523-531.

v. Ali, F. (2016). Hotel website quality, perceived flow, customer satisfaction and purchase intention. Journal of Hospitality and Tourism Technology.

vi. Breiby, M. A., \&Slåtten, T. (2018). The role of aesthetic experiential qualities for tourist satisfaction and loyalty. International Journal of Culture, Tourism and Hospitality Research.

vii. Cao, M., Zhang, Q., \&Seydel, J. (2005). B2C e-commerce web site quality: an empirical examination. Industrial Management \& Data Systems. 
viii. Chan, N. L., \&Guillet, B. D. (2011). Investigation of social media marketing: how does the hotel industry in Hong Kong perform in marketing on social media websites? Journal of Travel \& Tourism Marketing, 28(4), 345-368.

ix. Cheng, F.-F., Wu, C.-S., \& Yen, D. C. (2009). The effect of online store atmosphere on consumer's emotional responses-an experimental study of music and colour. Behaviour \& Information Technology, 28(4), 323-334.

x. Collins, D. (2018). Using Graphics to Inspire Failing Students Higher Education Computer Science (pp. 95-109): Springer.

xi. Currie, S. L., McGrath, P. J., \& Day, V. (2010). Development and usability of an online CBT program for symptoms of moderate depression, anxiety, and stress in post-secondary students. Computers in Human Behavior, 26(6), 1419-1426.

xii. Dayour, F., Adongo, C. A., \&Agyeiwaah, E. (2020). Continuous intention to use mobile money (MM) services: Driving factors among small and medium-sized tourism and hospitality enterprises (SMTHEs). Africa Journal of Management, 1-30.

xiii. Dresang, E. T. (2005). Access: The information-seeking behavior of youth in the digital environment. Library Trends, 54(2), 178-196.

xiv. Duarte, P., e Silva, S. C., \& Ferreira, M. B. (2018). How convenient is it? Delivering online shopping convenience to enhance customer satisfaction and encourage e-WOM. Journal of Retailing and Consumer Services, 44, 161169.

xv. Eppler, M. J. (2006). Managing information quality: Increasing the value of information in knowledge-intensive products and processes: Springer Science \& Business Media.

xvi. Ewusi-Mensah, K. (2012). Problems of information technology diffusion in sub-Saharan Africa: the case of Ghana. Information Technology for Development, 18(3), 247-269.

xvii. Frascara, J., Meurer, B., van Toorn, J., \& Winkler, D. (1997). User-centred graphic design: Mass communication and social change: CRC Press.

xviii. Gentilini, U., Almenfi, M., Orton, I., \& Dale, P. (2020). Social Protection and Jobs Responses to COVID-19.

xix. Goh, S. K., Jiang, N., Hak, M. F. A., \& Tee, P. L. (2016). Determinants of smartphone repeat purchase intention among malaysians: a moderation role of social influence and a mediating effect of consumer satisfaction. International Review of Management and Marketing, 6(4).

xx. Gretzel, U., Fuchs, M., Baggio, R., Hoepken, W., Law, R., Neidhardt, J., ... Xiang, Z. (2020). e-Tourism beyond COVID-19: a call for transformative research. Information Technology \& Tourism, 1.

xxi. Hasanov, J., \& Khalid, H. (2015). The impact of website quality on online purchase intention of organic food in Malaysia: A WebQual model approach. Procedia Computer Science, 72(6), 382-389.

xxii. Hsu, C.-L., Chang, K.-C., \& Chen, M.-C. (2012). The impact of website quality on customer satisfaction and purchase intention: perceived playfulness and perceived flow as mediators. Information Systems and eBusiness Management, 10(4), 549-570.

xxiii. Jiradilok, T., Malisuwan, S., Madan, N., \&Sivaraks, J. (2014). The impact of customer satisfaction on online purchasing: A case study analysis in Thailand. Journal of Economics, Business and Management, 2(1), 5-11.

xxiv. Kasavana, M. L. (2000). Quality issues in hospitality web site design and operation. Journal of Quality Assurance in Hospitality \& Tourism, 1(1), 83-104.

xxv. Kasavana, M. L., Knutson, B. J., \&Polonowski, S. J. (1998). Netlurking: The future of hospitality Internet marketing. Journal of Hospitality \& Leisure Marketing, 5(1), 31-44.

xxvi. Kirillova, K., Fu, X., Lehto, X., \&Cai, L. (2014). What makes a destination beautiful? Dimensions of tourist aesthetic judgment. Tourism Management, 42, 282-293.

xxvii. Kirillova, K., \&Lehto, X. (2015). Destination aesthetics and aesthetic distance in tourism experience. Journal of Travel \& Tourism Marketing, 32(8), 1051-1068.

xxviii. Lee, K., Joshi, K., \& Bae, M. (2009). A cross-national comparison of the determinants of customer satisfaction with online stores. Journal of Global Information Technology Management, 12(4), 25-51.

xxix. Liang, C.-J., \& Chen, H.-J. (2009). A study of the impacts of website quality on customer relationship performance. Total Quality Management, 20(9), 971-988.

xxx. Liu, X., He, M., Gao, F., \&Xie, P. (2008). An empirical study of online shopping customer satisfaction in China: a holistic perspective. International Journal of Retail \& Distribution Management.

xxxi. MacKay, K. J., \&Fesenmaier, D. R. (1997). Pictorial element of destination in image formation. Annals of tourism research, 24(3), 537-565.

xxxii. Mahmoud, M. A., Kastner, A. N. A., \&Lartey, J. O. (2017). Internet-based relationship marketing: A sub-Saharan African perspective. Journal of Relationship Marketing, 16(3), 179-196.

xxxiii. Marchionini, G., \&Komlodi, A. (1998). Design of interfaces for information seeking. Annual review of information science and technology, 33, 89-130.

xxxiv. Mehrabian, A., \& Russell, J. A. (1974). An approach to environmental psychology: the MIT Press.

xxxv. Pelet, J.-É., \&Papadopoulou, P. (2012). The effect of colors of e-commerce websites on consumer mood, memorization and buying intention. European Journal of Information Systems, 21(4), 438-467.

xxxvi. Pereira, H. G., de FátimaSalgueiro, M., \& Rita, P. (2016). Online purchase determinants of loyalty: The mediating effect of satisfaction in tourism. Journal of Retailing and Consumer Services, 30, 279-291.

xxxvii. Perrin, A. (2015). Social media usage. Pew research center, 52-68.

xxxviii. Rieh, S. Y. (2002). Judgment of information quality and cognitive authority in the Web. Journal of the American society for information science and technology, 53(2), 145-161. 
xxxix. Ruthven, I., \& Kelly, D. (2011). Interactive information seeking, behaviour and retrieval: facet publishing.

xl. Shaw, R., Kim, Y.-k., \& Hua, J. (2020). Governance, technology and citizen behavior in pandemic: Lessons from COVID-19 in East Asia. Progress in disaster science, 100090.

xli. Shukla, A., Sharma, N. K., \& Swami, S. (2010). Website characteristics, user characteristics and purchase intention: mediating role of website satisfaction. International Journal of Internet Marketing and Advertising, 6(2), 142-167.

xlii. Tandon, U., Kiran, R., \&Sah, A. N. (2017). Customer satisfaction as mediator between website service quality and repurchase intention: An emerging economy case. Service Science, 9(2), 106-120.

xliii. Tatar, Ş. B., \&Eren-Erdoğmuş, İ. (2016). The effect of social media marketing on brand trust and brand loyalty for hotels. Information Technology \& Tourism, 16(3), 249-263.

xliv. Wangenheim, F. V., \&Bayón, T. (2007). The chain from customer satisfaction via word-of-mouth referrals to new customer acquisition. Journal of the Academy of Marketing Science, 35(2), 233-249.

xlv. Witz, A., Warhurst, C., \&Nickson, D. (2003). The labour of aesthetics and the aesthetics of organization. Organization, 10(1), 33-54.

xlvi. Xu, X., \&Schrier, T. (2019). Hierarchical effects of website aesthetics on customers' intention to book on hospitality sharing economy platforms. Electronic Commerce Research and Applications, 35, 100856. 